\title{
BIOGEOGRAPHY AND DIVERGENCE TIME ESTIMATES OF WOODY BAMBOOS: INSIGHTS IN THE EVOLUTION OF NEOTROPICAL BAMBOOS
}

\author{
EduARDo RuIZ-SANCHEZ \\ Instituto de Ecología, A. C. Actual adcription: University of California, Berkeley \\ email: ruizsanchez.eduardo@gmail.com
}

\begin{abstract}
The Neotropical woody bamboos are a monophyletic lineage with three subtribes in the Bambusoideae: Arthrostylidiinae, Chusqueinae and Guaduainae. The geographical distribution of these subtribes extends from Mexico, Central America, Caribbean Islands, to South America. In order to understand the biogeographical patterns and origin of these bamboos, a phylogeny of Neotropical woody bamboos was first inferred. Then divergence time estimation of particular nodes using a Bayesian approach and ancestral area reconstruction using S-DIVA were performed. The results suggest a Miocene origin of Neotropical bamboos where the subtribe Chusqueinae was the oldest, followed by the Arthrostylidiinae and the Guaduinae. The ancestral area reconstruction indicated a complex scenario in which the ancestral area for Chusqueinae was Andean South America followed by multiple dispersal events to Atlantic Brazil and Mesoamerica. Overall, the results support the hypothesis of a South American origin of the Neotropical woody bamboos, corroborated by the molecular dating, ancestral area reconstruction and the fossil record. Keywords: Andes, Atlantic forests, Mesoamerica, Neotropical woody bamboos, South America.
\end{abstract}

Resumen: Los bambúes leñosos Neotropicales son un linaje monofilético dentro de Bambusoideae con tres subtribus: Arthrostylidiinae, Chusqueinae y Guaduinae. La distribución geográfica de éstas va desde México, Centroamérica, Islas del Caribe hasta Sudamérica. Para entender los patrones biogeográficos y el origen de estos bambúes se realizó un análisis filogenético. Posteriormente las estimaciones de los tiempos de divergencia de nodos particulares bajo una aproximación Bayesiana y la reconstrucción de las áreas ancestrales utilizando S-DIVA fueron realizadas. Los resultados sugieren un origen en el Mioceno para los bambúes Neotropicales, donde la subtribu Chusqueinae fue la más antigua, seguida de Arthrostylidiinae y Guaduinae. La reconstrucción de las áreas ancestrales, indican un escenario complejo donde el área ancestral para Chusqueinae fueron Los Andes, seguido de múltiples eventos de dispersión hacia el bosque Atlántico y Mesoámerica. Los resultados soportan la hipótesis de un origen Sudamericano para los bambúes Neotropicales, corroborado por la datación molecular, la reconstrucción del área ancestral y el registro fósil.

Palabras clave: Andes, bambúes leñosos Neotropicales, bosque Atlántico, Mesoámerica, Sudamérica.

$\mathbf{T}$ he bamboo subfamily (Bambusoideae) is one of the thirteen known subfamilies in Poaceae (GPWG, 2001; Sánchez-Ken et al., 2007; Bouchenak-Khelladi et al., 2008). Comprising 80-90 genera and more than 1,500 species distributed world wide except in the Antarctica and Europe (McClure, 1966; Soderstrom and Ellis, 1987; Judziewicz et al., 1999; Ohrnberger, 1999), bamboos grow from see level up to $4,000 \mathrm{~m}$ in altitude and are economically important in Asia and South America (Judziewicz et al., 1999; Bystriakova et al., 2003).

The latest molecular phylogeny of Poaceae (BouchenakKhelladi et al., 2008) recovered two main supported clades where the Bambusoideae in the BEP clade is sister to the Pooideae (wheat subfamily) and these two are sister to the
Ehrhartoidaeae (rice subfamily) (see also GPWG, 2001). Bouchenak-Khelladi et al. (2008) found that the bamboo subfamily is monophyletic but found paraphyly in the Bambuseae (woody bamboos), while the Paleotropical and Neotropical woody bamboos are sister to the Olyreae (herbaceous bamboos), and this clade sister to temperate woody bamboos. These results were later confirmed by a multi-gene phylogeny of the Bambusoideae (Sungkaew et al., 2009). In the paraphyletic woody bamboos with nine recognized subtribes, only three subtribes, (Chusquineae, Guaduinae and Melocanniinae) have been recovered as monophyletic groups (Kelchner and Clark, 1997; Clark et al., 2007; RuizSanchez et al., 2008; Fisher et al., 2009; Sungkaew et al., 2009), and the rest of the subtribes are not monophyletic 
groups (Guo et al., 2001, 2002; Guo and Li, 2004; Clark et al., 2007; Yang et al., 2008; Bouchenak-Khelladi et al., 2008; Peng et al., 2008; Sungkaew et al., 2009; Triplett and Clark, 2010).

The Neotropical woody bamboos form a monophyletic lineage represented by three subtribes: Arthrostylidiinae, Chusqueinae, and Guaduinae (Clark et al., 1995; Judziewicz et al., 1999; Zhang and Clark, 2000; BouchenakKhelladi et al., 2008). The subtribe Arthrostylidiinae has 12 genera and more than 157 species and is distributed in South America, Mesoamerica and the Caribbean Islands, from sea level up to $3,700 \mathrm{~m}$. The Chusqueinae has only one genus, Chusquea, with more than 155 species distributed from Mexico to Brazil. Chusquea species grow from sea level up to $4,000 \mathrm{~m}$ in altitude and is one of the most speciose genera in the Poaceae. The Guaduinae has five genera and more than 40 species, is distributed from Mexico to Brazil, but never grows above 2,500 $\mathrm{m}$ in altitude. In some parts of Mesoamerica (Mexico and Costa Rica) and South America (Brazil and Colombia) species of the three subtribes are sympatric (Judziewicz et al., 1999). The three Neotropical subtribes have distributions in three main areas of highest bamboo diversity and endemism; Brazil, the Northern and Central Andes, and Mexico. Brazil (including the Amazon basin and the Atlantic forests) has the greatest diversity of genera and species, followed by the Andes (Venezuela to Bolivia), and Mexico and Central America (Soderstrom et al., 1988; Clark, 1990; Judziewicz et al., 1999).

The Poaceae originated in the late Cretaceous (c. $96 \mathrm{Ma}$ ) and the center origin was either African or South American regions of Gondwana, based on three plastid markers and four fossil calibration points (Bouchenak-Khelladi et $a l ., 2010)$. The BEP clade has been inferred to have originated in the early Eocene in closed habitats in Africa, according with the results of the ancestral area reconstructions of Bouchenak-Khelladi et al. (2010). The diversification of bamboos occurred during the Miocene (23.7 to 5.3) as documented by macrofossils or pollen fossil records (Berry, 1929; Thomasson, 1987; Crepet and Feldman, 1991; Worobiec and Worobiec, 2005; Brea and Zucol, 2007; Worobiec et al., 2009). However, the crown node of the Bambusoideae originated $30 \mathrm{Ma}$ in the middle Oligocene (Bouchenak-Khelladi et al., 2010). Clark (1997) proposed that the woody bamboos, arose in the Southern Hemisphere in lowland, tropical areas and then radiated into tropical montane habitats.

The uplift of the Andean in the Miocene had a profound impact on the history of South America; it changed the course of the Amazon river system from northwestwards to the Atlantic side (Hoorn et al., 1995). The Andean uplift acted both as a dispersal route and as driver in promoting rapid diversification, via allopatric speciation and ecological displacement, in highland and montane habitats (Antonelli et al., 2009). On the other hand, the climatic fluctuations due the Milankovitch cycles caused global changes in the distribution of tropical forests during the Cenozoic (Tertiary-Quaternary) and before (Haffer and Prance, 2001). The Andean uplift and the climate change are responsible for Amazonian forest refugia, where many extant plant and animal species probably originated (Haffer and Prance, 2001). Almost at the same time during the late Miocene in Central America the migration of the magmatic front from the Cordillera del Aguacate to the Cordillera Central resulted in relocation of the Pacific-Caribbean drainage divide, formation of the Valle Central basin, and reorganization of fluvial networks (Marshall et al., 2003), making a complex topographic scenario for plant divergence. South America was the primary center of origin for the New World woody bamboos, and dispersal to Mesoamerica (Central America to Mexico) occurred after the Panamanian land bridge formed about 2.8-2.9 Ma (Judziewicz et al., 1999; Bartoli et al., 2005).

Due to the limited sample of neotropical woody bamboos (three and four respectively) in previous phylogenetic and biogeographic studies (i.e. Sungkaew et al., 2009; Bouchenak-Khelladi et al., 2010), we used the molecular data from Kelchner and Clark (1997) and Ruiz-Sanchez et al. (2008) to reconstruct a dated phylogenetic tree of the Neotropical woody bamboos. This paper aims to study the temporal patterns of Neotropical woody bamboos biogeography and temporal evolution: (1) producing a dated phylogenetic tree of the subfamily Bambusoideae and the Neotropical woody lineage, (2) inferring the evolution of geographical range and reconstructing ancestral areas, and (3) inferring biogeographical patterns of dispersal-vicariance from South America to Mesoamerica based on fossil and Yule based divergence estimation and ancestral area reconstruction.

\section{Material and methods}

Phylogeny of the Neotropical woody bamboos. In order to infer the most complete Neotropical woody bamboo species phylogeny, 46 taxa were used. The plastid rpll6 intron was used to infer the phylogeny, the sequences were Genbank downloaded <http://www.ncbi.nlm.nih.gov/genbank/> (consulted August 25 2010) following the previous phylogenetic analyses of Kelchner and Clark (1997) and Ruiz-Sanchez et al. (2008). Bayesian analyses were conducted using MrBayes 3.2.1 (Huelsenbeck and Ronquist, 2001; Ronquist and Huelsenbeck, 2003). First, jMODELTEST.0.1.1 (Posada, 2008) was run to identify the model of evolution using the AIC values. The best model for the rpll6 intron was TIM1+G. Then the model's parameters were used in MRBAYES v. 3.1.2 (Ronquist and Huelsenbeck, 2003). Two parallel BMCMC were executed simultaneously with default options and each was run for $10^{7}$ generations. Trees were sampled every 2,000 generations yielding 1,000 trees 
saved per run. Stationarity was verified graphically by plotting the number of generations versus $-\ln \mathrm{L}$ values. Trees prior to stationarity were excluded (10\%) and the remaining trees were used to generate a majority consensus tree with the Bayesian posterior probabilities of the clades.

Divergence time estimation. The estimation of divergence time was done under a Bayesian approach as implemented in BEAST v. 1.5.4 (Drummond and Rambaut, 2007). Two different estimations of divergence times were run. First, we estimated the divergence time of the Bambusoideae subfamily using five plastid regions ( $r n L$ intron, $t r n L-F$ intergenic spacer, $a t p B-r b c L$ intergenic spacer, $r p s 16$ intron, and matK gene) and 64 taxa of Sungkaew et al. (2009). This first estimation was done, due the majority of the Bambusoideae and Neotropical woody bamboo taxa (52 and 4) and plastid (five) markers used in the Sungkaew et al. (2009) study, instead the 25 and three bambusoids and three plastid markers used by Bouchenak-Khelladi et al. (2010). The finality was to obtain the best divergence estimation times for the Neotropical woody bamboos and to use it to calibrate the Neotropical tree priors.

BEAST v. 1.5.4 has three substitution models (HKY, GTR and TN93) and three site heterogeneity models (gamma, invariant sites, or gamma + invariant sites). We used the model of selection GTR $+\mathrm{G}$ based on the result of AIC from jMODELTEST 0.1.1 to the subfamily Bambusoideae under an uncorrelated lognormal relaxed clock model. We constrained five nodes to be monophyletic according to Sungkaew et al. (2009) and Bouchenak-Khelladi et al. (2010): BEP-P, Ehrarthoideae, Pooideae, Bambusoideae and Panicoideae. The Yule speciation process was used to model the tree prior. Five calibration points were used to determine specific nodes prior, and lognormal distributions following the results of Bouchenak-Khelladi et al. (2010). The divergence time of BEP-P (57 Ma, 51-75 Confidence Interval) [lognormal mean 4.04, SD 0.14, zero offset 0] was used to calibrate the root node. The Ehrarthoideae crown group was (53 Ma, 49-66 CI ) [lognormal mean 3.97, SD 0.12, zero offset 0]. The Pooideae crown group was (44 Ma, 40-57) [lognormal mean 3.78, SD 0.14, zero offset 0]. The Bambusoideae crown group was (29 Ma, 26-48 CI) [lognormal mean 3.36, SD 0.26, zero offset 0]. Finally, the Panicoideae crown group was (24 Ma, 22-35 CI) [lognormal mean 3.17, SD 0.2, zero offset 0].

A second estimation of divergence times was conducted for the Neotropical woody bamboos. Sequences for both analyses were aligned manually using the program Se-Al v. 2.0a11 (Rambaut, 2002). We used the HKY + G model of sequence evolution for the 46 data matrix of the rpll6 intron, under an uncorrelated lognormal relaxed clock model and Yule speciation process was used to model the tree prior. The three Neotropical subtribes and the genus Guadua were constrained to be monophyletic according to (Ruiz-Sanchez et al., 2008 and Fisher et al., 2009). Two fossil calibration points were used to determine specific node priors. For Chusqueinae-Chusquea crown group, the age of Miocene macrofossil from Colombia (Berry, 1929) was used, approximating a median age of $14 \mathrm{Ma}$ [lognormal mean 2.63, SD 0.1, zero offset 0] and for the Guadua crown group, the age of a Pliocene macrofossil from Argentina (Brea and $\mathrm{Zu}-$ col, 2007) was used, approximating a median age of $4.5 \mathrm{Ma}$ [lognormal mean 1.5, SD 0.1, zero offset 0].

To calibrate the root we used the results of the first divergence time estimation of the Bambusoideae, using the estimated $19.37 \mathrm{Ma}$ [lognormal mean 3.23, SD 0.26, zero offset 0; range of 6.7-22.6 Ma] divergence time for the Neotropical woody bamboos lineage crown group.

For both divergence time estimations we performed four independent $10^{7}$ generation runs with random starting trees, sampling every 2,000 generations. Results were analysed using TRACER v. 1.5 (Rambaut and Drummond, 2007) Available from the BEAST site at $<$ http://tree.bio.ed.ac.uk/ software/tracer/> to assess convergence and effective sample sizes (ESS) for all parameters and the tree files from the four runs of BEAST were combined. Finally, these results were summarized in a single tree and the two resulting trees were visualized in FIGTREE v. 1.5.4 (Drummond and Rambaut, 2007). Available from the BEAST site at <http://tree. bio.ed.ac.uk/software/figtree/>

Ancestral area reconstruction. Four areas were defined for the biogeographic analysis based on three main biogeographical areas with highest bamboo diversity and endemism identified by Soderstrom et al. (1988); Clark (1990); Judziewicz et al. (1999) and following the biogeographic areas of Antonelli et al. (2009). The four areas were coded as follow: Meosamerica (including Mexico and Central America) (A), Andes (B), Amazonian basin (C) and Brazilian Atlantic forests (D). Dispersal-Vicariance Analysis (DIVA) is one of the most widely-used methods for inferring biogeographic histories (Ronquist, 1997, 2001). DIVA reconstructs the ancestral distribution in a phylogeny using a three-dimensional step matrix, while allowing for dispersal and extinction to occur. One problem with the current implementation of DIVA is that it ignores the uncertainty in phylogenetic inference: ancestral areas are reconstructed onto a fixed tree topology assuming that the phylogeny is known without error (Nylander et al., 2008). A second source of uncertainty in DIVA is associated with ancestral area optimization: multiple equally parsimonious optimal distributions are often suggested at ancestral nodes, particularly if there are many widespread extant distributions (Ronquist, 1997, Nylander et al., 2008). To avoid the problems with DIVA the S-DIVA (Statistical Dispersal-Vicariance Analyses) was used integrating 10,000 trees from the Bayesian analysis. S-DIVA determines statistical support for ancestral range reconstructions (Yu et al., 2010). The 
frequencies of an ancestral range at a node in ancestral reconstructions are averaged over all trees and each alternative ancestral range at a node is weighted by the frequency of the node occurring, or by some other measure of support for the node (Yu et al., 2010).

\section{Results}

Phylogeny of neotropical woody bamboos. The total number of base pairs of the aligned rpl16 intron matrix was 1,075, where 43 bp were variable and 1,032 were constant. Bayesian majority consensus rule retrieved a topology where two (Guaduinae and Chusqueinae) of the three Neotropical sub- tribes show posterior probabilities $\geq 0.85$ (PP) (Figure 1). However, the sister relationships of Guaduinae and Arthrostylidiinae are well supported (PP : 1.0). Within the Guaduinae, three genera (Eremocaulon, Guadua, and Otatea) have $\mathrm{PP}>0.9$, and the Otatea subclade is part of the Olmeca (O. clarkiae and $O$. fulgor) clade but with low PP support. In the Arthrostylidiinae only the Rhipidocladum pittieri and $R$. racemiflorum subclade are well supported (PP : 1.0) and the clade of Aulonemia laxa and A. patula subclade has 0.87 PP support. In the Chusqueinae subtribe there are several subclades well supported ( $\mathrm{PP}>0.93$; Figure 1).

Divergence time estimation. Results from divergence time

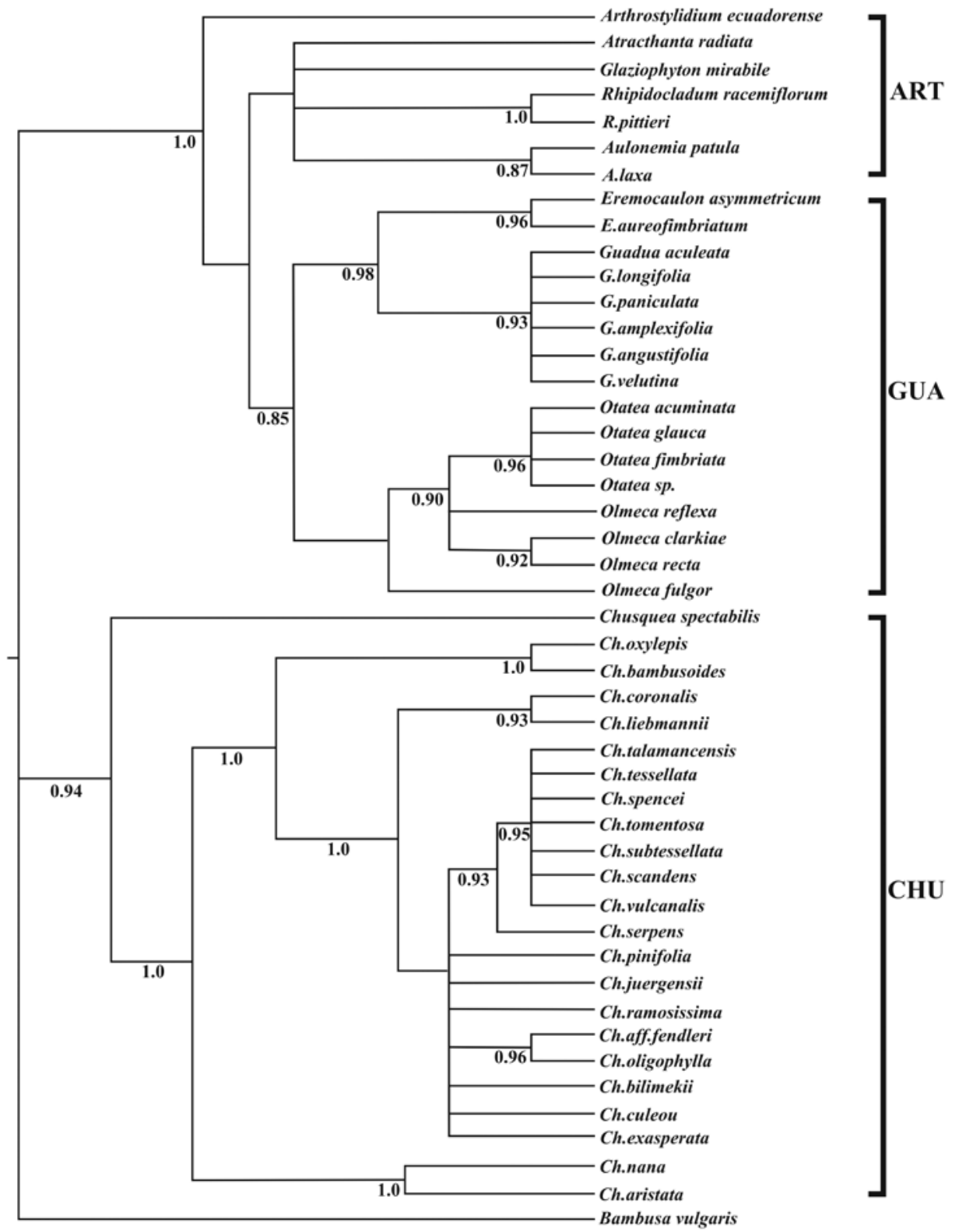

Figure 1. Bayesian consensus tree where posterior probabilities are shown below the branches. Brackets identify subtribes: ART, Arthrostylidiinae; GUA, Guaduinae and CHU, Chusqueinae. 


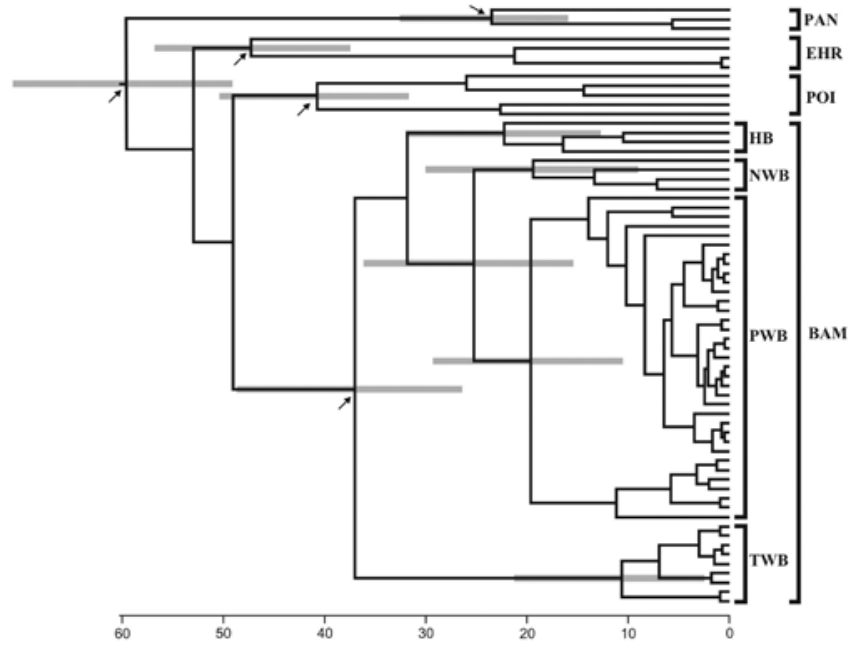

Figure 2. Chronogram based on a Bayesian approach of the Bambusoideae and related subfamilies. Gray bars indicate $95 \%$ confidence intervals of node age estimations. Brackets identify subfamilies and bamboos lineages: BAM, Bambusoideae; EHR, Ehrhartoideae; PAN, Panicoideae; POI, Pooideae; HB, herbaceous bamboos; NWB, neotropical woody bamboos; PWB, paleotropical woody bamboos and TWB, temperate woody bamboos. Black arrows indicate calibration points.

estimations for the Bambusoideae subfamily using the Yule speciation process are visualized in Figure 2. The four main lineages (Temperate, Paleotropical and Neotropical woody bamboos, and herbaceous bamboos) of the Bambusoideae showed different divergence times. Herbaceous bamboos have a divergence time of 22.3 (95\% HPD) Ma. Paleotropical woody bamboos have 19.6 (95\% HPD) Ma. Neotropical woody bamboos 19.3 (95\% HPD) Ma, this date was used to calibrate the root. Finally the Temperate woody bamboos are the younger with 10.6 (95\% HPD) Ma (Figure 2).

The divergence time estimation for the Neotropical woody bamboos showed that the Chusqueinae was the oldest with divergence times of 14.2 Ma (11.6-16.8 CI, 95\% HPD), followed by the Arthrostylidiinae with 9.1 Ma (4.914.2 CI, 95\% HPD); the Guaduinae is the youngest subtribe with 8.8 Ma (5.3-13.1 CI, 95\% HPD) (Figure 3). Chusquea is the oldest genus in Neotropical woody bamboos, but with diversification during the Pliocene to Pleistocene (4.6$0.5 \mathrm{Ma}$ ) (Figure 3). In the Arthrostylidiinae, Aulonemia and Rhipidocladum diverged in the Pliocene (4.4 Ma) and Pleistocene (1.2 Ma) respectively. In the Guaduinae, Gua$d u a$ and Eremocaulon diverged in the Pliocene (4.1 and 3.2 Ma), Otatea during the Pleistocene (1.9 Ma) and Olmeca species including $O$. clarkiae in the middle Pliocene (4.3 Ma) (Figure 3).

Ancestral area reconstruction. The statistical dispersal-vicariance analyses reconstructed the ancestral distributions of all Neotropical woody bamboos as being restricted to one or a few areas. The ancestral distribution area of Neotropical woody bamboos is restricted either to Mesoamerica + Andes + Atlantic forests $(53.35 \%)$ or to Mesoamerica + Andes (46.65\%). S-DIVA infers rather complex scenarios with wider ancestral ranges being inferred for increasingly interior nodes (Figure 3). Of the 44 cladogenic events in Figure 3, S-DIVA required 24 dispersal events to explain the observed pattern of distribution. Dispersal rather than vicariance appears to have been of key importance in shaping Neotropical woody bamboos distribution patterns (Figure 3). The ancestral distribution area of the Chusqueinae are the Andes (71.88\%), or Andes + Atlantic forests (28.12\%); for the Guaduinae is Mesoamerica (100\%); and for the Arthrostylidiinae are Mesoamerica (46.90\%), Andes + Atlantic forests $(21.06 \%)$, Mesoamerica + Atlantic forests $(16.71 \%)$ or Mesoamerica + Andes + Atlantic forests (15.31\%) (Figure 3).

\section{Discussion}

The close relationships between the Arthrostylidiinae and Guaduinae as sister groups and the absence of node support for the Arthrostylidiinae subtribe has been found in previous phylogenetic analyses (Kelchner and Clark, 1997; Guala et al., 2000; Zhang and Clark, 2000; BouchenakKhelladi et al., 2008; Ruiz-Sanchez et al., 2008; Sungkaew et al., 2009). The Chusqueinae is corroborated as sister to the Arthrostylidiinae+Guaduinae clade, with good node support as in previous phylogenetic analyses (Kelchner and Clark, 1997; Ruiz-Sanchez et al., 2008; Sungkaew et al., 2009; Fisher et al., 2009).

According to molecular dating of the Bambusoideae (Figure 2) the ancestral bamboo lineage originated in the late Eocene (37 Ma [26.5-48.7 CI, 95\% HPD]), eight Ma older than the Bouchenak-Khelladi et al. (2010) estimates, but with the same confidence interval. This change could be due the inclusion of five plastid markers in the Bambusoideae dating instead of three plastid markers used by Bouchenak-Khelladi et al. (2010).

The oldest Neotropical woody bamboo lineage estimated in our analyses is the subtribe Chusqueinae with 14.2 (11.6-16.8 CI, 95\% HPD) Ma in the middle Miocene, at the same time in South America when extensive lakes and inland seas in the foreland basin in western Amazonia were developed (Lundberg et al., 1998) and the newly-formed montane habitats must have acted as an ecological barrier to lowland taxa (Antonelli et al., 2009). The fossil record from Colombia dated to the Miocene and assigned to Chusquea (Berry, 1929) corroborated the molecular dating found for the Chusqueinae. However there is a bamboo fossil record older than Berry's fossil dated to the Eocene from Argentina (Frenguelli and Parodi, 1941). This fossil indicated an older origin (Eocene) of Neotropical woody bamboos than the molecular dating (Miocene) here presented. If this bamboo 


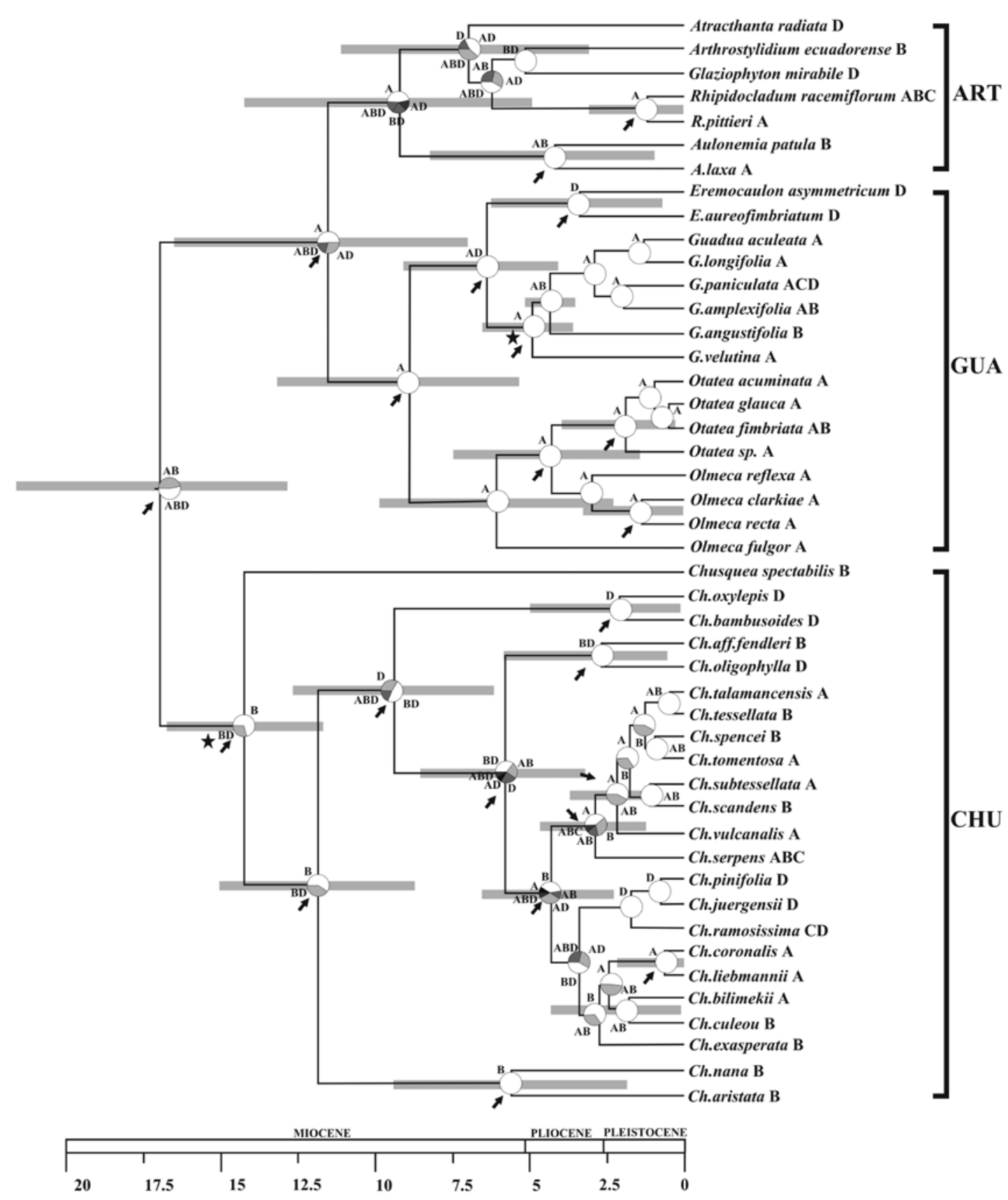

Figure 3. Combined chronogram and biogeographic analysis of Neotropical woody bamboos. Gray bars indicate $95 \%$ confidence intervals of node age estimations. Node charts show the relative probabilities of alternative ancestral distributions obtained by integrating Statistical Dispersal-Vicariance Analyses (S-DIVA). The first five areas with highest probability are colored according to their relative probability in the following order: white $>$ light gray $>$ gray $>$ dark gray $>$ black. Black arrows indicate clades with a posterior probability $>0.85$. Present range for each species are given after the species name. Brackets identify subtribes: ART, Arthrostylidiinae; GUA, Guaduinae and CHU, Chusqueinae. Areas used in the biogeographic analysis. A, Mesoamerica (Mexico and Central America), B, Andes, C, Amazon basin and D, Atlantic forests. Black stars indicate fossil calibration points.

fossil record could be confirmed as Eocene in origin, the history of the Bambusoideae would change, with an South American bamboo origin and prior dispersal to Europe or Asia. Other bamboo fossils have been reported in Europe, since the Oligocene through the Pliocene (Worobiec and
Worobiec, 2005) where they are now extinct.

The Guaduinae subtribe has an origin of 8.8 Ma (5.3-13.1 CI, 95\% HPD) in the late Miocene. Brea and Zucol (2007) describe a fossil species assigned to Guadua (G. zuloagae) from Argentina. This fossil species was recorded in sedi- 
ments of the Pliocene and coincided with the diversification of Guadua during the Pliocene according to the molecular dating (Figure 3). The guaduoid genus Otatea originated during the Pleistocene (1.96; 0.33-4.09 CI, 95\% HPD).

Based on the results of the ancestral area reconstruction, the Neotropical woody bamboos have wider ancestral ranges (Mesoamerica + Andes + Atlantic forests). However, taking into account the older node of the Neotropical woody bamboos that correspond to Chusqueinae lineage, where the ancestral area corresponds to Andean South America. This scenario is in agreement with the hypothesis of Clark (1997) that the Neotropical woody bamboos have a South American origin and this is in accord with the fossil record of Chusquea from Colombia in the Miocene (Berry, 1929) and the correct identity of the fossil of Frenguelli and Parodi (1941), is needed to corroborate this scenario. The migration from South America to Mesoamerica after the completion of the Panama isthmus (Judziewicz et al., 1999) is valid only for the Chusqueinae, because the ancestral area reconstruction for the Arthrostylidiinae and Guaduinae indicate a Mesoamerican origin. However, the Guadua zuloagae fossil found in Argentina in sediments of the Pliocene contradicts these results. The limited Guadua samples used in the molecular divergence time estimations and in the ancestral area reconstruction could be the responsible of this contradiction.

Bouchenak-Khelladi et al. (2010) postulated two scenarios of bamboo spread from the Old to the New World one via the North America Atlantic Land Bridge (NALB) and Bering Land Bridge. The African + European + North America bamboo fossils (Thomasson, 1987; Strömberg, 2005; Worobiec and Worobiec, 2005) give more support for the first via. The spread to South America, could have occurred along a dispersal route via the NALB until the late Eocene-early Oligocene, and finally to South America, which was connected by the Greater Antilles, the Bahamas platform, the Aves Ridge and perhaps the site of the present Lesser Antilles (Bouchenak-Khelladi et al., 2010). Under this scenario, the fossil of Frenguelli and Parodi (1941) from the Eocene corroborated this hypothesis. The scenario of NALB could be explained for the presence of bamboo-like grasses in the fossil record of North America in the early Oligocene and have been proposed for other angiosperm lineages (Chanderbali et al., 2001; Donoghue, 2008; Antonelli et al., 2009). On the other hand, the same fossil from Argentina and our divergence time estimations for the Bambusoideae with an Eocene origin on this subfamily supported the contrary hypothesis of a South American origin of the bamboos. The inclusion of more herbaceous, Neotropical and Paleotropical bamboos samples that represents the complete geographical distribution of the bamboos in a new phylogeny, and to estimate the divergence times and reconstructing the ancestral area distribution could give new light in understanding the evolution and the biogeography of the bamboos.

\section{Conclusions}

The results here presented, indicate a Miocene origin of the Neotropical woody bamboos with an ancestral area in Andean South America with multiple dispersal events to Atlantic Brazil and Mesoamerica. However, to corroborate the scenarios of spread from the Old to the New World or a possible South America origin of bamboos followed by dispersals to the Old World, a complete phylogeny is needed. This is a first approximation to understanding the biogeography and divergence times of the Neotropical woody bamboos. However the addition of more molecular markers (cpDNA or nrDNA) and more taxa of Arthrostylidiinae from South America and the Antilles as well as Guaduinae (Guadua and Apoclada) and Chusquea species and the corroboration of the Frenguelli and Parodi's fossil will improve our understanding of the evolution and biogeography of the Neotropical bamboos.

\section{Acknowledgements}

I thank Juan Francisco Ornelas for his excellent review of this paper that helped me to improve it substantially. Thanks to Francisco and Maria Rodriguez for improving the English version of the manuscript. I also thank two anonymous reviewers whose suggestions greatly improved the manuscript. Part of this work was carried out by using the resources of the Computational Biology Service Unit from Cornell University which is partially funded by Microsoft Corporation.

\section{Literature cited}

Antonelli A., Nylander J.A.A., Persson C. and Sanmartín I. 2009. Tracing the impact of the Andean uplift on Neotropical plant evolution. Proceedings of the National Academy of Science of the United States of America 106:9749-9754.

Bartoli G., Sarnthein M., Weinelt M., Erlenkeuser H., GarbeSchönberg D. and Lea D.W. 2005. Final closure of Panama and the onset of northern hemisphere glaciation. Earth and Planetary Science Letters 237:33-44.

Berry E.W. 1929. Tertiary fossil plants from Colombia, South America. Proceedings of the United States National Museum 75, Art. 24:1-12.

Bouchenak-Khelladi Y., Salamin N., Savolainen V., Forest F., van der Bank M., Chase M.W., and Hodkinson T.R. 2008. Large multi-gene phylogenetic trees of the grasses (Poaceae): progress towards complete tribal and generic level sampling. Molecular Phylogenetics and Evolution 47:488-505.

Bouchenak-Khelladi Y., Verboo G.A., Savolainen V., and Hodkinson T.R. 2010. Biogeography of the grasses (Poaceae): a phylogenetic approach to reveal evolutionary history in geographical space and geological time. Botanical Journal of the Linnean Society 162:543-557.

Brea M. and Zucol A.F. 2007. Guadua zuloagae sp. nov., the first 
petrified bamboo culm record from the Ituzaingó Formation (Pliocene), Paraná Basin, Argentina. Annals of Botany 100:711723.

Bystriakov, N., Kapos V., Stapleton C. and Lysenko I. 2003. Bamboo Biodiversity. Information for Planning Conservation and Management in the Asia-Pacific Region. United Nations Environment Programme-World Conservation Monitoring Centre and International Network for Bamboo and Rattan, Cambridge.

Chanderbali A.S., Van Der Werff H. and Renner S.S. 2001. Phylogeny and historical biogeography of Lauraceae: evidence from the chloroplast and nuclear genomes. Annals of the Missouri Botanical Garden 88:104-134.

Clark L.G. 1990. Diversity and biogeography of Neotropical bamboos (Poaceae: Bambusoideae). Acta Botanica Brasilica 4:125132

Clark L.G. 1997. Bamboos: The centrepiece of the grass family. In: Chapman G.P. Ed. The Bamboos, pp. 237-248, Academic Press, London.

Clark L.G., Zhang W. and Wendel J.F. 1995. The phylogeny of the grass family (Poaceae) based on $n d h \mathrm{~F}$ sequence data. Systematic Botany 20:436-460.

Clark L.G., Dransfield S., Triplett J. and Sánchez-Ken J.G. 2007. Phylogenetic relationships among the one-flowered, determinate genera of Bambuseae (Poaceae: Bambusoideae) In: Columbus J.T., Friar E.A., Hamilton, C.W., Porter J.M., Prince L.M. and Simpson M.G. Eds. Monocots: Comparative Biology and Evolution-Poales, pp. 315-332, Rancho Santa Ana Botanic Garden, Claremont.

Crepet W.L. and Feldman, G.D. 1991. The earliest remains of grasses in the fossil record. American Journal of Botany 78:1010-1014.

Donoghue M.J. 2008. A phylogenetic perspective on the distribution of plant diversity. Proceedings of the National Academy of Sciences of the United States of America 105:11549-11555.

Drummond A.J. and Rambaut A. 2007. BEAST: Bayesian evolutionary analysis by sampling trees. BMC Evolutionary Biology 7:214.

Fisher A.E., Triplett J.K., Ho C-S., Schiller A.D., Oltrogge K.A., Schroder E.S., Kelchner S.A. and Clark L.G. 2009. Paraphyly in the bamboo subtribe Chusqueinae (Poaceae: Bambusoideae) and a revised infrageneric classification for Chusquea. Systematic Botany 34:673-683.

Frenguelli J. and Parodi L.R. 1941. Una Chusquea fósil de El Mirador (Chubut). Notas del Museo de La Plata Tomo 6, Paleontología 32:235-238.

GPWG [Grass Phylogeny Working Group], Barker N.P., Clark L.G., Davis J.I., Duvall M.R., Guala G.F., Hsiao C, Kellogg E.A. and Linder H.P. 2001. Phylogeny and subfamilial classification of the grasses (Poaceae). Annals of the Missouri Botanical Garden 88:373-457.

Guala G.F., Bogler D., Sadle J. and Francisco-Ortega J. 2000. Molecular evidence for polyphyly in the genus Apoclada (Poaceae: Bambusoideae). Bamboo Science and Culture 14:15-20.

Guo Z.H. and Li D.Z. 2004. Phylogenetics of the Thamnocalamus group and its allies (Gramineae: Bambusoideae) inferred from the sequences of GBSSI gene and ITS spacer. Molecular Phylogenetics and Evolution 30:1-12.

Guo Z.H., Chen Y.Y., Li D.Z. and Yang J.B. 2001. Genetic variation and evolution of the alpine bamboos (Poaceae: Bambusoideae) using DNA sequence data. Journal of Plant Research
114:315-322.

Guo Z.H., Chen Y.Y. and Li D.Z. 2002. Phylogenetic studies on Thamnocalamus group and its allies (Bambusoideae: Poaceae) based on ITS sequence data. Molecular Phylogenetics and Evolution 22:20-30.

Haffer J. and Prance G.T. 2001 Climatic forcing of evolution in Amazonia during the Cenozoic: on the refuge theory of biotic differentiation. Amazoniana 16:579-607.

Hoorn C., Guerrero J., Sarmiento G.A. and Lorente M.A. 1995. Andean tectonics as a cause of changing drainage patterns in Miocene northern South America. Geology 23:237-240.

Huelsenbeck J.P. and Ronquist F. 2001. MrBAYES: Bayesian inference of phylogenetic trees. Bioinformatics 17:754-755.

Judziewicz E.J., Clark L.G., Londoño, X. and Stern, M.J. 1999. American Bamboos. Smithsonian Institution Press, Washington, D.C.

Kelchner S.A. and Clark L.G. 1997. Molecular evolution and phylogenetic utility of the chloroplast rpll6 intron in Chusquea and the Bambusoideae (Poaceae). Molecular Phylogenetics and Evolution 8:385-397.

Lundberg J.G., Marshall L.G., Guerrero J., Horton B., Malabarba M.C.S.L. and Wesselingh F. 1998. The stage for Neotropical fish diversification: A history of tropical South American rivers. In: Malabarba L.R., Reis R.E., Vari R.P., Lucena Z.M. and Lucena C.A.S. Eds. Phylogeny and Classification of Neotropical Fishes, pp. 13-48, EdiPUCRS, Porto Alegre.

Marshall J.S., Idleman B.D., Gardner T.W. and Fisher D.M. 2003. Landscape evolution within a retreating volcanic arc, Costa Rica, Central America. Geology 31:419-422.

McClure F.A. 1966. The Bamboos: A Fresh Perspective. Harvard University Press, Cambridge.

Nylander J.A.A., Olsson U., Alström P. and Sanmartín I. 2008. Accounting for phylogenetic uncertainty in biogeography: a Bayesian approach to dispersal-vicariance analysis of the thrushes (Aves: Turdus). Systematic Biology 57:257-268.

Ohrnberger D. 1999. The Bamboos of the World. Annotated Nomenclature and Literature of the Species and the Higher and Lower Taxa. Elsevier Science, Amsterdam.

Peng S., Yang H.Q. and Li D.Z. 2008. Highly heterogeneous generic delimitation within the temperate bamboo clade (Poaceae: Bambusoideae): evidence from GBSSI and ITS sequences. Taxon 57:799-810.

Posada D. 2008. jModelTest: Phylogenetic model averaging. Molecular Biology and Evolution 25:1253-1256.

Rambaut A. 2002. Se-Al Sequence Alignment Editor, v2.0a11. Department of Zoology, University of Oxford, Oxford.

Rambaut A. and Drummond A.J. 2007. Tracer v1.5, <http://beast. bio.ed.ac.uk/Tracer> (consulted December 2, 2009)

Ronquist F. 1997. Dispersal-vicariance analysis: A new approach to the quantification of historical biogeography. Systematic Biology 46:195-203.

Ronquist F. 2001. DIVAversion 1.2. Computer program for MacOS and Win32. Evolutionary Biology Centre, Uppsala University. Available at <http://www.ebc.uu.se/systzoo/research/diva/diva. html $>$ (consulted August 25, 2010)

Ronquist F. and Huelsenbeck J.P. 2003. MrBayes 3: Bayesian phylogenetic inference under mixed models. Bioinformatics. 19:1572-1574.

Ruiz-Sanchez E., Sosa V. and Mejía-Saules M.T. 2008. Phylogenetics of Otatea inferred from morphology and chloroplast 
DNA sequence data and recircumscription of Guaduinae (Poaceae: Bambusoideae). Systematic Botany 33:277-283.

Sánchez-Ken J.G., Clark L.G., Kellogg E.A. and Kay E.E. 2007. Reinstatement and emendation of subfamily Micrairoideae (Poaceae). Systematic Botany 32:71-80.

Soderstrom T.R. and Ellis R.P. 1987. The position of bamboo genera and allies in a system of grass classification. In: Soderstrom, T.R., Hilu, K.W., Campbell, C.S. and Barkworth, M.E. Eds. Grass Systematics and Evolution, pp. 225-238, Smithsonian Institution Press, Washington, D.C.

Soderstrom T.R., Judziewicz E.J. and Clark L.G. 1988. Distribution patterns of neotropical bamboos. In: Vanzolini P.E., Heyer W.R. Eds. Proceedings of a Workshop on Neotropical Distribution Patterns, pp. 121-157, Academia Brasileira de Ciencias, Rio de Janeiro.

Strömberg C.A.E. 2005. Decoupled taxonomic radiation and ecological expansion of open-habitat grasses in the Cenozoic of North America. Proceedings of the National Academy of Science of the United States of America 102:11980-11984.

Sungkaew S., Stapleton C.M.A., Salamin N. and Hodkinson T.R. 2009. Non-monophyly of the woody bamboos (Bambuseae; Poaceae): a multi-gene region phylogenetic analysis of Bambusoideae s.s. Journal of Plant Research 122:95-108.

Thomasson J.R. 1987. Fossil grasses: 1820-1986 and beyond. In: Soderstrom T.R., Hilu K.W., Campbell C.S. and Barkworth
M.E. Eds. Grass Systematics and Evolution, pp. 159-167. Smithsonian Institution Press, Washington, D.C.

Triplett J.K. and Clark L.G. 2010. Phylogeny of the temperate bamboos (Poaceae: Bambusoideae: Bambuseae) with an emphasis on Arundinaria and allies. Systematic Botany 35:102120.

Worobiec E. and Worobiec G. 2005. Leaves and pollen of bamboos from the Polish Neogene. Review of Paleobotany and Palynology 133:39-50.

Worobiec E., Worobiec G. and Gedl P. 2009. Occurrence of fossil bamboo pollen and a fungal conidium of Tetraploa cf. aristata in Upper Miocene deposits of Józefina (Poland). Review of Palaeobotany and Palynology 157:211-217.

Yang H.Q., Yang J.B., Peng Z.H., Gao J., Yang Y.M., Peng S. and Li D.Z. 2008. A molecular phylogenetic and fruit evolutionary analysis of the major groups of the Paleotropical woody bamboos (Gramineae: Bambusoideae) based on nuclear ITS, GBSSI gene and plastid trnL-F DNA sequences. Molecular Phylogenetics and Evolution 48:809-824.

Yu Y., Harris A.J. and He X. 2010. S-DIVA (Statistical DispersalVicariance Analysis): A tool for inferring biogeographic histories. Molecular Phylogenetics and Evolution 56:848-850.

Zhang W. and Clark L.G. 2000. Phylogeny and classification of the Bambusoideae (Poaceae). In: Jacobs, S.W.L. and Everett, J.E. Eds. Grasses: Systematics and Evolution, pp. 53-42, CSIRO

Received: September 8, 2010

Accepted: February 9, 2011 